\title{
RESEARCH ARTICLE \\ Isolation, Purification and Characterization of Sericin Protein from the Discharge Water of Silk Industry
}

\author{
Pon. Sathya Moorthy
}

Department of Nano Science \& Technology, Tamil Nadu Agricultural University, Coimbatore-641003

\begin{abstract}
Sericin is a silk worm secreting protein occurring naturally as a silk cocoon.It is a typical example of a natural core-shell structure. Silk cocoon constitutes about $75 \%$ of core silk fibroin (SF) and $25 \%$ of shell silk sericin (SS). Silk fibroin has a potential application in the textile and biomedical field due to its inherent mechanical strength. Sericin is a hydrophilic protein that has a greater affinity with silk fibroin; hence it binds with silk fibroin coaxially to protect pupa from predators, temperature variations, moisture, mechanical abrasions, etc.. During the commercial production of raw silk fiber, sericin will be degummed by treating the cocoon with hot water at high temperatures and discharged as wastewater after extraction of silk fibroin from cocoons. Sericin protein posse's potential application in the field of cosmetics as an additive in skin moisturizer, shampoo, anti-wrinkle creams due to the presence of hydroxyl amino acids, wound healing, promoting cell growth and differentiation in pharmaceutical industries due to its biological origin without causing an undesirable immunological response. Sericin protein was extracted from discharge water collected from the silk industry was purified and characterized using SDS-PAGE, FTIR, CD, SEM, DSC \& TG-DTA was reported.
\end{abstract}

\section{Keywords: Sericin; Silk fibroin; Silk cocoon; Circular dichroism; Scanning electron microscope; Spray drying.}

\section{INTRODUCTION:}

Sericin is a natural hydrophilic protein derived from silk worm. Sericin has a potential application in skin moisturizer due to high content of hydroxyl amino acids and its anti-wrinkle action (Engel et. al., 1987). Sericin was reported to have diverse biological activities, such as anti-oxidation, UV-resistant, anti-coagulation, wound healing, promoting cell growth and differentiation (Baba et al., 1996, Kato et al., 1998, Sasaki et al., 2000, Takeuchi et al., 2005, Miyazaki et al., 2004, Hazeri et al., 2012, Aramwit et al., 2010, Padol et al., 2012). Sericin has recently been found to activate the proliferation of several cell-lines. Sericin is now widely used as an additive in cosmetics and in cell culture media due to its moisturizing effect and cell-protecting action (Padamwar et al., 2005, Voegeli et al., 1993, Takahashi et al., 2005., Terada et al., 2005). Sericin can form a gel by itself, or as copolymer can be formed as a film or a scaffold with good characteristics that can be used in the cosmetic and pharmaceutical industries. Sericin is proven to cause no immunological responses, which has resulted in a more acceptable material for biological applications (Aramwit et al., 2012). In the food industry, sericin peptides showed functional properties to the development of new products with like antioxidant properties and metal ion-chelating activity due to the high amount of hydroxyl bonds derived from some amino acids like serine and acid aspartic (Sasaki et al., 2000, Wu et al., 2008). Silk is a high molecular weight natural protein polymer that has been approved as a biomaterial by the U.S. Food and Drug Administration (FDA), which has classified it as a non-absorbable material according to US Pharmacopeia (Cao et al., 2009). Synthetic polymers like polylactic acid (PLA), polyglycolic acid (PGA), poly-lactic-co-glycolic acid (PLAGA), polycaprolactone, and natural biopolymers, such as silk, keratin, elastin, collagen, fibrin clot etc. are extensively used as biopolymers because of their biological properties. The natural materials are of considerable interest due to their structural properties and superior biocompatibility (Padol et al., 2012).

Generally, the purification of sericin was carried out using silk cocoons. Purification of sericin can be achieved using different available methods, namely, 
(a). urea extraction (Aramwit et al, 2010), (b). Boiling of heat extraction (Sothornvit et al., 2010) (c). Acid extraction (Khan et al, 2010), (d). Soap and alkali extraction (Rajkhowa et al., 2011), enzymatical extraction (Gulrajani et al, 2000) and High pressure \& High-temperature extraction (Gulrajani et al, 2009).In this paper, sericin protein was isolated, purified, and characterized from discharge water collected from a silk reeling unit.

\section{MATERIALS AND METHODS:}

\section{Reagents:}

Ethanol, Coomassie brilliant blue (CBB) and Tris- $\mathrm{HCl}$, were purchased from Sigma Aldrich, India. Dialysis bag (LA387) was purchased from HIMEDIA. High-Range-2 Protein Marker (14- 220 kDa) was purchased from SRL chemicals (Cat No: 99625). All the chemicals were used without further purification.

\section{Isolation and purification of sericin protein:}

Discharge water containing sericin protein was discarded readily after recovering silk fibers from the cocoons. Discharge water was collected in a container from silk reeling unit located at Vadavalli, Coimbatore. It was allowed to stand at room temperature for 4 hours to cool down. Discharge water was then kept at $4^{\circ} \mathrm{C}$ overnight to settle down the dissolved sericin. The supernatant solution was decanted cautiously without disturbing precipitate. Precipitate containing maximum sericin was recovered and treated with pre-cooled ethanol $<10^{\circ} \mathrm{C}$ at the ratio of $1: 4$ and allowed to stand for $4 \mathrm{~h}$ at the same temperature. Precipitation of sericin was obviously observed in the container. The supernatant was aspirated without disturbing the settled precipitate. Precipitated sericin was centrifuge at 4,000 RPM for $5 \mathrm{~min}$. The remaining supernatant was aspirated and discarded. The recovered precipitate was suspended in $1 \mathrm{M}$ Tris buffer at pH. 9.0 and dialyzed against the same buffer at $20^{\circ} \mathrm{C}$ for 48 hours. Dialyzed sericin solution was recovered by spinning at 10,000 RPM for 5 min to recover the suspension and preserved for further use. The concentration of sericin protein was quantified as $0.4 \mathrm{mcg} / \mathrm{mcl}$ using Analytic Jena SPECORD 210 Plus, UV-Vis spectrometer (available at the Department of Nano Science \& Technology, Tamil Nadu Agricultural University, Coimbatore).

\section{RESULTS AND DISCUSSION}

\section{Characterization of sericin protein}

\section{SDS- PAGE analysis}

Homogeneity of sericin protein was confirmed by using 10\% SDS PAGE. High-Range-2 Protein Marker (14- 220 kDa), SRL Cat No: 99625, was loaded in the lane: $1.20 \mu$ l of purified protein solution containing $8 \mu g$ of sericin is loaded along with loading buffer in the lane: 2 . The instrument is allowed to run at $100 \mathrm{~V}$ for 1 hour. Gel was recovered and stained with coomassie brilliant blue solution for 2 hours and rinsed with distilled water. Gel was destained using de-staining solution. The developed gel was saved and imaged. A single band in lane: 2 at 70 75 kDa clearly exhibits its homogeneity.

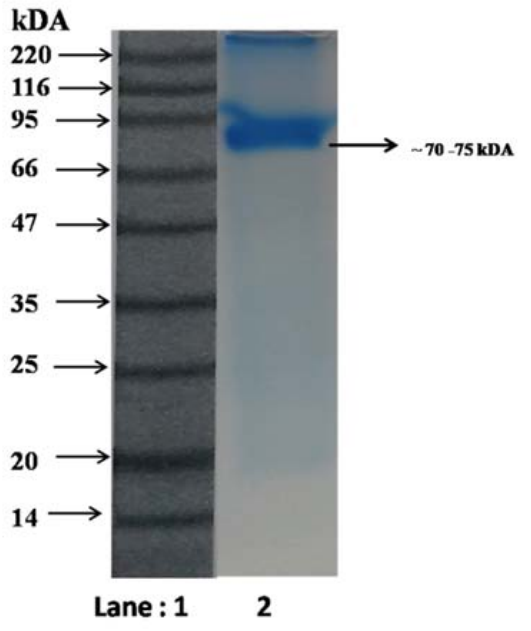

Figure 1. Poly Acrylamide Gel Electrophoresis showing

Lane: 1 Protein marker, Lane: 2 Purified sericin protein at 70-75 kDa

\section{Circular Dichroism Spectrometry (CD) analysis :}

The differential absorption of left and right circularly polarized light at a particular wavelength can distinguish the secondary structures of protein. The secondary structure analysis of sericin was carried out in continuous mode within the Far UV range of 190-250 $\mathrm{nm}$ with the data interval and scan rate of $0.1 \mathrm{~nm}$ and $50 \mathrm{~nm} / \mathrm{min}$. respectively, of using Jasco CD spectroscopy (Model: J-815, available at CLRI, Chennai). The spectral details of sericin were analyzed using software Descriptive Secondary Structure of Protein (DSSP). Spectral analysis of sericin protein was found to exhibit secondary structural details as, Helix (37\%), Beta sheets (0\%), Turns (40.2\%) and Random coils (22.7\%). A secondary structural detail of the sericin protein was shown in Fig. 2.

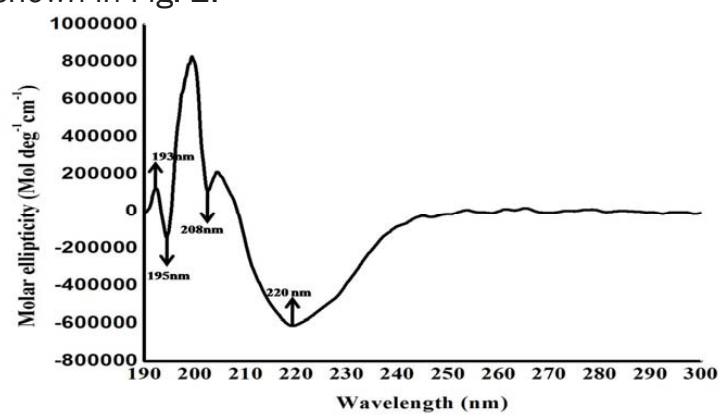

Figure 2. CD spectra for sericin protein exhibiting secondary structure details, Helix $(37 \%)$ showing +ve band at $193 \&$-ve band at $208 \& 220 \mathrm{~nm}$, Beta Sheets (0)\% not showing Anti parallel ß-Sheet: +ve

$107 \mid 10-12$ | 2 
band at $195 \mathrm{~nm} \&$ - ve band at $218 \mathrm{~nm}$, Turn (40.2\%) showing -ve band at $195 \mathrm{~nm}$ \& low ellipticity above 210nm, Random coils (22.7\%).

\section{FTIR analysis}

Purified sericin was subjected to FTIR analysis. Sericin was analyzed with Thermo Nicolet 650
FTIR spectrophotometer (available at Bharathiar University) with scanning range of $400-4000 \mathrm{~cm}^{-1}$. Transmittance at $3350 \mathrm{~cm}^{-1}$ is due to $\mathrm{N}-\mathrm{H}$ stretching in resonance with overtone amide II, $1639 \mathrm{Cm}^{-1}$ is due to $80 \% \mathrm{C}=0$ stretching, $10 \% \mathrm{~N}-\mathrm{H}$ bending and $657 \mathrm{~cm}^{-1}$ is due to $\mathrm{OH}$ bending. A satellite peak is observed in between 3000 to $1800 \mathrm{~cm}^{-1}$.

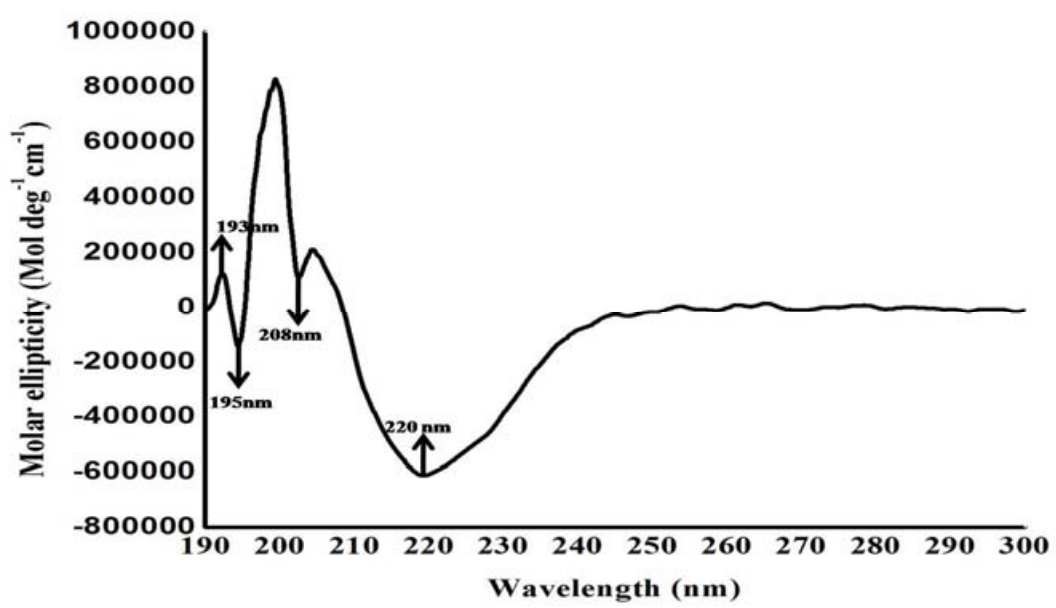

Figure 3. FTIR spectra of sericin protein showing peaks at $3350 \mathrm{Cm}^{-1}$ due to $\mathrm{N}-\mathrm{H}$ stretching in resonance with amide II overtone, $1639 \mathrm{Cm}^{-1}$ due to $\mathrm{C}=0$ stretching $(80 \%), \mathrm{N}-\mathrm{H}$ bending $(10 \%), \mathrm{C}-\mathrm{N}$ stretching $(10 \%)$

\section{Scanning Electron Microscopy imaging}

The purified sericin was spray-dried using B90

Butchi Switzerland (available at Department of
Nano Science \& Technology, Tamil Nadu Agricultural University, Coimbatore) spray drier with an inlet and outlet temperature of $115^{\circ} \mathrm{C}$ and $65^{\circ} \mathrm{C}$, respectively.

\section{Spray dried sericin}
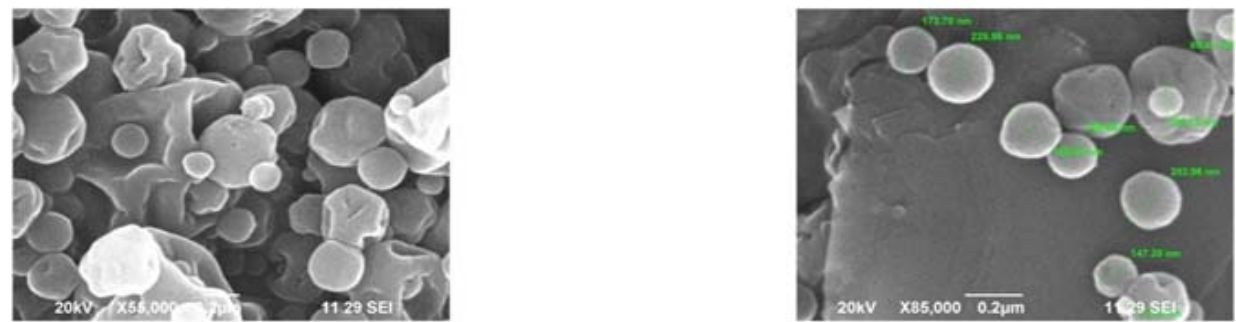

\section{Freeze dried sericin}
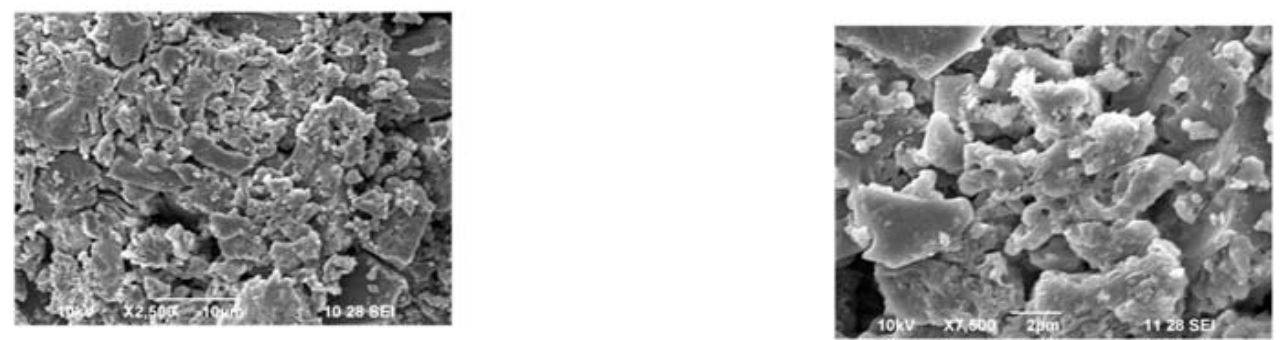

Figure 4. SEM image of spray-dried and freeze-dried sericin. Spray-dried sericin is spherical in shape with a diameter of $\mathbf{9 0 - 2 3 0} \mathrm{nm}$. Freeze-dried sericin resembles flakes with irregular shapes. 
Spray-dried samples were collected, stored and imaged using SEM at 10-20 KV. Spray-dried sericin looks globular in shape within the nano range of 90 to $230 \mathrm{~nm}$. Sericin solution was taken in round bottom flask and rolled on the ice bath to make a frozen thin coating inside the flask to increase the surface area and lyophilized using Lark, Penguin Classic lyophilizer (available at Department of Nano Science \& Technology, Tamil Nadu Agricultural University, Coimbatore)at $-80^{\circ} \mathrm{C}$ and 0.1 Pascal. Freeze-dried sericin resembles irregular flakes.

\section{Differential Scanning Calorimetry analysis (DSC) analysis:}

Thermal analysis of sericin protein was carried out using DSC and TGA analysis (SDT Q600 V20.9 Build 20 (available at Amirtha Vishwa Vidhyapeetham University, Coimbatore). DSC spectra of sericin protein were drawn between heat flow along $\mathrm{Y}$-axis and temperature along $\mathrm{X}$-axis. As the temperature rises from $0^{\circ} \mathrm{C}$ to $350^{\circ} \mathrm{C}$ a slow and gradual absorption of heat is absorbed till $108^{\circ} \mathrm{C}$. A sharp fall of heat flow is absorbed between $108^{\circ} \mathrm{C}$ to $119^{\circ} \mathrm{C}$ may be due to the loss of moisture content and $254^{\circ} \mathrm{C}$ to $263^{\circ} \mathrm{C}$ clearly shows an endothermic nature of the protein. Since the absorption of heat is observed above $100^{\circ} \mathrm{C}$ enables sericin to be a potential protein in thermostable application.

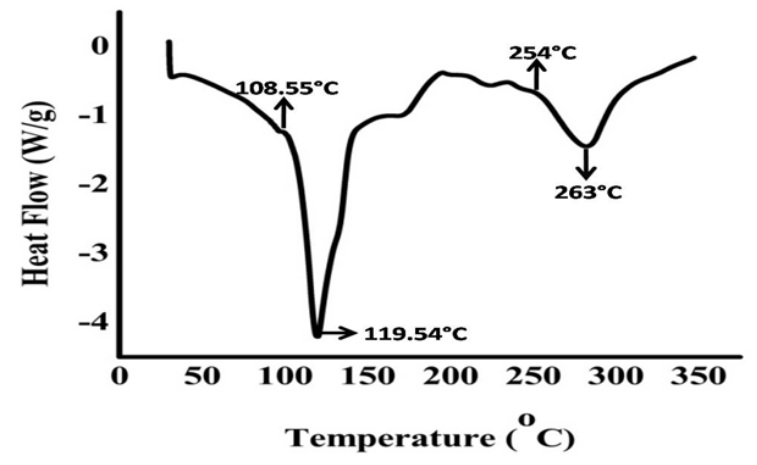

Figure 5. Differential Scanning Calorimetric spectral analysis of sericin protein.

\section{Thermo Gravimetry- Differential Thermal} Analysis

Differential Scanning Calorimetry and Thermo Gravimetric Analysis spectra for sericin protein was plotted between weight $(\mathrm{mg})$ and Deriv.Weight $\left(\% /{ }^{\circ} \mathrm{C}\right)$ in $\mathrm{Y}$-axis Vs. Temperature $\left({ }^{\circ} \mathrm{C}\right)$ in X-axis. Sericin protein $(5 \mathrm{mg})$ was taken for TG-DTA analysis between $0-600^{\circ} \mathrm{C}$ with the ramp temperature of about $10^{\circ} \mathrm{C}$ per minute in nitrogen atmosphere. As the temperature of the sample increases, the randomness of the protein increases due to the uptake of temperature till $62^{\circ} \mathrm{C}$ (endothermic) and above $62^{\circ} \mathrm{C}$ there is a steep rise in the spectra up to $104.97^{\circ} \mathrm{C}$ reflects absorption of the temperature of the protein (exothermic). The percentage of weight loss absorbed between $62^{\circ} \mathrm{C}$ to $104.97^{\circ} \mathrm{C}$ is $3.18 \%$ may be due to loss of moisture from the protein. Similarly, the exothermic peaks are observed at $136.71^{\circ} \mathrm{C}, 208.81^{\circ} \mathrm{C}, 267.45^{\circ} \mathrm{Cand} 412.17^{\circ} \mathrm{C}$. The percentage of weight loss absorbed between $62^{\circ} \mathrm{C}$ to $104.97^{\circ} \mathrm{C}$ is $19.18 \%$ may be due to breakage of some organic and inorganic bond in the sample

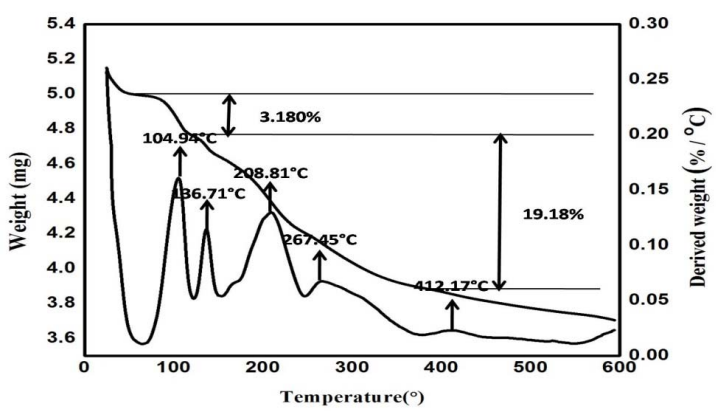

Figure 6. TG-DTA analysis of sericin protein

\section{CONCLUSION}

Generally, proteins are fragile in nature and stabilized by hydrogen and Vander Waals bond by the presence of the solvent molecules (40-50\%). Sericin purified from discharge water was characterized using SDS-PAGE determines its homogeneity, circular dichroism depicts its secondary structure profile, FTIR analysis of sericin exhibits the presence of amide and peptide bond, DSC \& TG -DTA analysis of sericin clearly explain its tolerance to the temperature upto $100^{\circ} \mathrm{C}$, SEM imaging of spraydried and freeze-dried sericin exhibits a spherical and flake-like structures. Sericin protein extracted for the discharge water retains the properties like homogeneity, secondary structural profile, and temperature tolerance which can also be used in some potential applications.

\section{Acknowledgement}

The author gratefully acknowledges DST SERB, India, for financial assistance.

\section{Reference}

W. Engle, U. Hoppe, W. Pape, G. Sauermann. 1987. Properties of a sericin-containing buffering shampoo, Medical Cosmetology 1, 2, 91-110.

Baba, T.,Hanada, K. \&Hashimoto, I. 1996. The study of ultraviolet b-induced apoptosis in cultured mouse keratinocytes and in mouse skin. J Dermatol. Sci 12, 18-23.

Kato N, Sato S, Yamanaka A, Yamada H, Fuwa N, et al. 1998. Silk protein, sericin, inhibits lipid peroxidation and tyrosinase activity. Biosci Biotechnol Biochem 62: 145-147.

Sasaki, M., Kato, N.,Watanabe, H. \& Yamada, H. 2000. Silk protein, sericin, suppresses colon carcinogenesis induced by 1, 2-dimethylhydrazine in mice. Oncol Rep 7, 1049-1052. 
Akari Takeuchi, Chikara Ohtsuki, Toshiki Miyazaki, Masanobu Kamitakahara, Shin-ichi Ogata, Masao Yamazaki, Yoshiaki Furutani, Hisao Kinoshita, and Masao Tanihara. 2005. Heterogeneous nucleation of hydroxyapatite on protein: Structural effect of silk sericin. J R Soc Interface $\mathbf{2}$, 373-378,

Miyazaki, T. et al. 2004. Control of bioresorption of porous alpha-tricalcium phosphateby coating with silk sericin. Trans. Mater Res. Soc. Jpn 29, 4.

Najmeh Hazeri, Hossein Tavanai and Ali Reza Moradi. 2012. Production and properties of electrosprayed sericin nanopowder, Sci. Technol. Adv. Mater. 13035010, (2012).

Aramwit, P., Damrongsakkul, S., Kanokpanont., S. and Srichana., T. 2010. Biotechnol. Appl. Biochem. 55, 91.

Padamwar, M. N., Pawar, A. P., Daithankar, A. V., and Mahadik, K. R. 2005. Silk sericin as a moisturizer: an in vivo study. J. Cosmet. Dermatol., 4, 250-257.

Voegeli, R., Meier, J., and Blust, R. 1993. Sericin silk protein:unique structure and properties. Cosmet. Toiletries, 108, 101-108.

Takahashi, M., Tsujimoto, K., Kato, Y., Yamada, H., Takagi, H., and Nakamori, S., 2005. A sericinderived peptide protects Sf9 insect cells from death caused by acute serum deprivation. Biotechnol. Lett. 27, 893-897.

Terada, S., Sasaki, M., Yanagihara, K., and Yamada, H., (2005). Preparation of silk protein sericin as mitogenic factor for better mammalian cell culture. J. Biosci. Bioeng., 100, 667-671.

Pornanong Aramwit, Tippawan Siritientong and Teerapol Srichana. 2012. Potential applications of silk sericin, a natural protein from textile industry byproducts, Waste Manag Res. 30(3), 217-224.

Sasaki M, Yamada H, Kato N. Consumption of silk protein, sericin elevates intestinal absorption of zinc, iron, magnesium and calcium in rats. Nutrit Res 2000; 20,1505-1511.
Wu JH, Wang Z, Xu SY. 2008. Enzymatic production of bioactive peptides from sericin recovered from silk industry wastewater. Proc Biochem. 43, 480. 487.

Yang Cao, Bochu Wang, Biodegradation of silk biomaterials. (2009). Int. J. Mol. Sci. 10, 1514-1524.

Amol R. Padol, K. Jayakumar, N.B. Shridhar, H.D. Narayana Swamy1, K. Mohan, Manochaya S. 2012.Efficacy of the silk protein based biofilms as a novel wound healing agent, International Journal of Toxicology and Applied Pharmacology 2(3): 31-36

Gulrajani, M.L., Agarwal, R., Chand, S. 2000. Degumming of silk with fungal protease', Indian Journal of Fiber and Textile Research, 25, 138-142.

Gulrajani, M. L., Purwar, R., Prasad, R. K., Joshi, M. (2009) Studies on structural and functional properties of sericin recovered from silk degumming liquor by membrane technology', Journal of Applied Polymer Science, 113, 2796-2804.

Aramwit, P., Siritientong, T., Srichana, T. (2012) Potential applications of silk sericin, a natural protein from textile industry by-products', Waste Management and Research, 30 (3), 217-224.

Rajkhowa, R., Wang, L. J., Kanwar, J. R., Wang, X. G. 2011. Molecular weight and secondary structure change in Eri Silk during alkali degumming and powdering', Journal of Applied Polymer Science,119, 1339-1347.

Khan, M. I., Ahmadb, A., Khan, S. A., Yusuf, M., Shahid, M., Manzoor, N., Mohammad, F. 2011. Assessment of antimicrobial activity of Catechu and its dyed substrate', Journal of Cleaner Production, 19, 1385-1394.

Greenfield NJ. 2006, Determination of the folding of proteins as a function of denaturants, osmolytes or ligands using circular dichroism. Nat Protoc. 1(6):2733-2741. 